\title{
Introduction: the value of peripheral nerve surgery
}

\author{
Robert J. Spinner, MD, ${ }^{1}$ Holly S. Gilmer, MD, ${ }^{2}$ and Gregory R. Trost, MD³ \\ 'Department of Neurosurgery, Mayo Clinic, Rochester, Minnesota; ${ }^{2}$ Pediatric Neurosurgery, William Beaumont Hospital, Royal \\ Oak, Michigan; and ${ }^{3}$ Department of Neurological Surgery, University of Wisconsin Hospital and Clinics, Madison, Wisconsin \\ If a single picture is worth a thousand words, then a video, by logical extension, would be priceless. This edition show- \\ cases peripheral nerve surgery in all its grandeur and preserves it for posterity. Classic and novel surgical techniques are \\ shown related to tumor biopsy or resection; nerve decompression for entrapment; and nerve reconstruction with direct \\ repair or nerve transfer. Akin to a nautical chart filled with detailed maps for sailors, this Neurosurgical Focus Video Atlas \\ provides navigational tools for neurosurgeons. The shared underlying message is that a sound knowledge of anatomy \\ can lead to innovation (i.e., creative approaches or solutions) and excellence (i.e., improved patient outcomes).
}

KEYWORDS peripheral nerve surgery; surgical technique; video 